\title{
Remedial Teaching in Mathematics through Multisensory Strategies
}

\author{
Mrs.C. Mattuvarkuzhali \\ Asst.Professor ,Dhanalakshmi Srinivasan college of education, Perambalur.
}

\begin{abstract}
Quality human resources enhance the progress and prosperity of any nation. Excellent educational system produces good citizens. Our current educational system should be revitalized which produces creative, talented and co-operative people according to the recent global pressure.

In the present $21^{\text {st }}$ century the explosion of technologies uplift the world into the sky. It leads to globalization. We require powerful brainy citizens for this competitive world. Education can give tremendous boost to these citizens in the global society. Education should not only reflect the needs of the society but also excellence. Every effort should make to adopt our educational system today's changing economic and social realities of the scientific world. No branch of science is complete without mathematics. Mathematical understanding and reasoning are essential components of success in all walks of life. How did this precious mathematics subject teach or learn? Being abstract nature of mathematics most of the student find difficult to perceive it. Teachers are constantly looking for ways or tools to help their pupils understand the underlying concepts of the lessons. Attention is too paid on the integrative efforts of Information Processing Approach, Transformation between Short Term Memory and Long Term Memory and accelerating cognitive strategies. In this situation the investigators adopt some remedial measures through Multisensory strategies to overcome from these difficulties and enhance the understanding of the learners. This paper focuses about it.
\end{abstract}

\section{Introduction:}

In the present $21^{\text {st }}$ century the explosion of technologies uplift the world into the heaven in the sky. It leads to globalization. We require powerful brainy citizens for this competitive world. Education can give tremendous boost to these citizens in the global society. Education should not only reflect the needs of the society but also excellence. Every effort should make to adopt our educational system today's changing economic and social realities of the scientific world. No branch of science is complete without mathematics. Mathematical understanding and reasoning are essential components of success in all walks of life. How did this precious mathematics subject teach or learn? I am a mathematics teacher having 18 years of experience, with my experience and observations I found that the following difficulties among the secondary and higher secondary students.

* More than half of the students incorrectly measure the units.

- Often get confusion between the areas and volumes in the word problem and between square and cubic units.

* Students performance on measurement task decreases significantly when the numbers are in fraction.

- Students have poor understanding in random and non- random distribution of objects.

* Poor understanding in the algebraic identities.

* Students have find difficulties in solving algebraic word problems.

- Difficulties in trigonometrically ratios for the beginners of trigonometric concept.

* Understanding in trigonometry identities.

* Application of integral calculus

- Some students are memorizing the concept without understanding.

Teachers need to include in each teaching presentation at least three (3) basic learning modalities (auditory, visual, and tactile), to meet the needs of most students, is a common thread among researchers. (Caudill, 1998; Gadt-Johnson, 2000; Willis, 2001).In this situation the investigators adopt some remedial measures through Multisensory strategies to overcome from these difficulties and enhance the understanding of the learners. This paper focuses on it.

\section{Multisensory strategies in mathematics teaching}

Enjoying something means being able to participate with confidence and take pleasure from the experience. One does not have to be a mountaineer to derive pleasure from walking up a hill! We seem to lose the meaning of enjoying learning when we try to get all children to achieve the same end result at the same time. Almost all math curriculums are text-based, auditory style programs (remember reading is an auditory activity, 
not a visual activity because reading involves words processed as language, and not visual image processing). "When students are able to represent a problem or mathematical situation in a way that is meaningful to them, it becomes more accessible. Using representation - whether drawings, mental images, concrete materials, or equations - helps students organize their thinking and try various approaches that may lead to a clearer understanding and a solution. (Fennell \& Rowan, 2001)".Mathematics is an abstract and cognitive subject. Being abstract nature of mathematics most of the student find difficult to perceive it. Teachers are constantly looking for ways or tools to help their pupils understand the underlying concepts of the lessons. Multi-sensory instruction is a highly creative instructional method and the strategy tailored to meet out the individual needs, abilities and learning styles. Learning mathematics through the multi-sensory integrated learning strategies are able to increase the students understanding and build a knowledge base for each of the content area effectively.

\section{Kinesthetic style: Learning through doing:}

The kinesthetic learners must "do" something to learn it. This person is actively involved in learning and loves to flex those large motor muscles. There is a lot of body movement going on when these learners are in their learning.

Students build false interpretations of geometrical terms from their exposure to a limited number of static pictures in text. For example many students claim that two lines cannot be parallel unless they are in the same length or are oriented vertically or horizontally.

Some students have some informal understanding of geometrical transformations such as reflection and rotation, but a difficult time operating as shapes using these transformations. For example they got misconception of figures like

\section{Instead of}
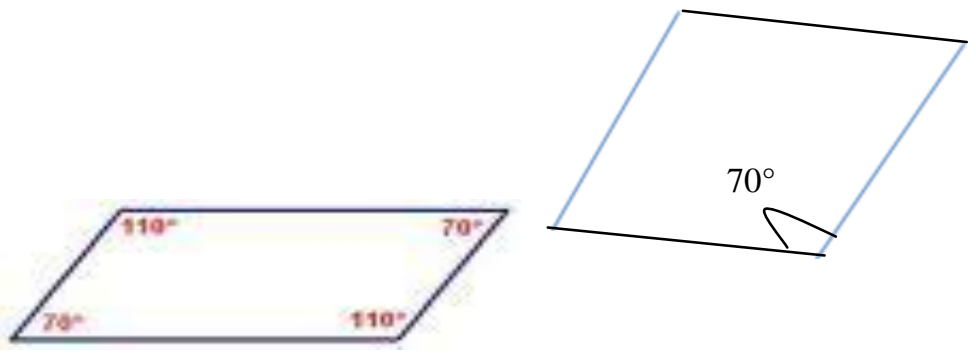

We must give practice with geometrical instruments to draw the following figures and make clearly understanding about the angles then ask them to make the full figures.
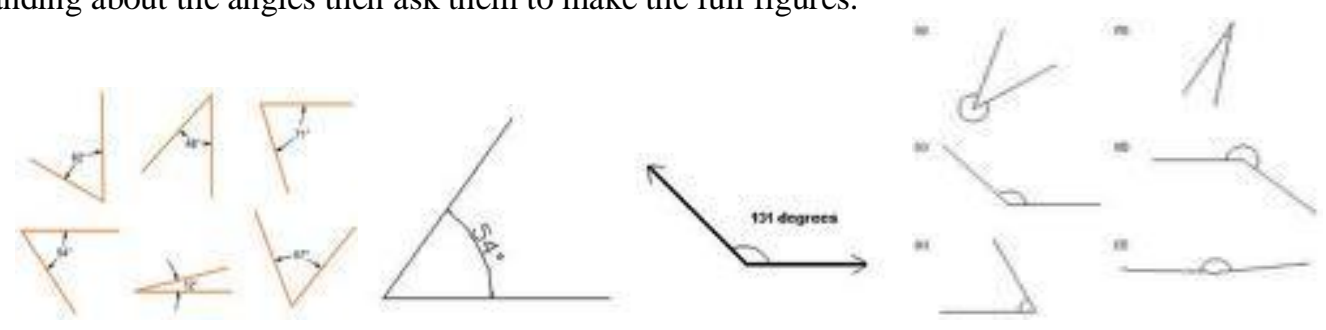

\section{Tactual style: Learning through sensations and teaching:}

The tactual learner learns through the sense of touch and small motor experiences. Tactual learners are also often aware of the emotional signals, subtle and blatant, that others send. They may be sensitive to odors in their environment. They often are adept at using their hands, and they benefit from touching things to get to know them better. These are the tree "hands-on" learners. Examples we show the clear figure of the Pythagoras theorem by means of Paper folding.
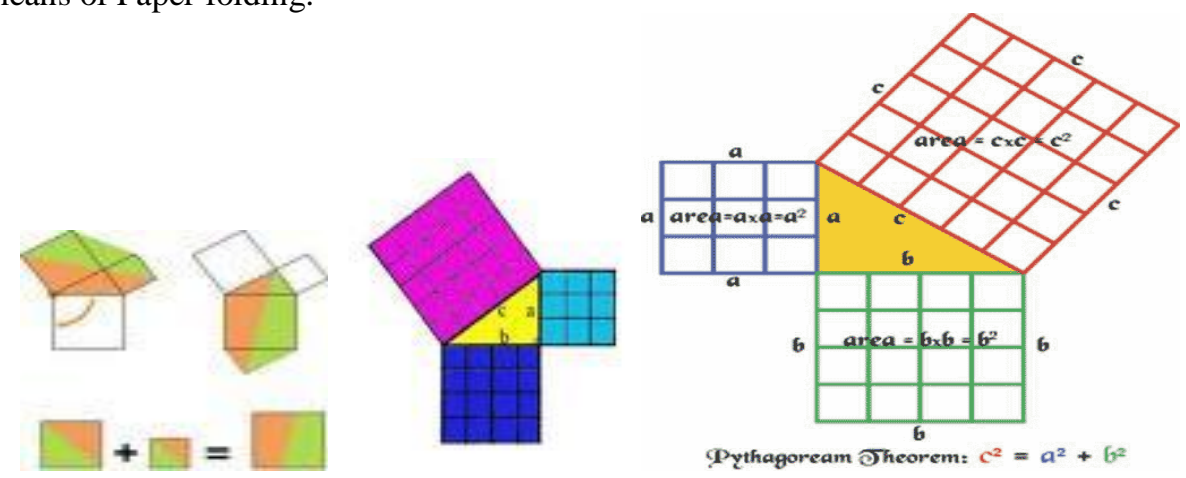


\section{Auditory style: Learning through hearing}

Auditory learners love discussion, and can readily be overheard by teachers in a classroom situation, describing mathematical relationships and thereby indicating the developing state of their insight and understanding of the topic begins learn by listening, remembering what was discussed rather than seen, speak in rhythmic patterns, talk to themselves while working ,move their lips and pronounce the words as they read ,enjoy reading aloud and listening, can repeat back and mimic, can find writing difficult, are better at telling , are frequently eloquent speakers are talkative, love discussion, and go into lengthy descriptions.

Example: we record the trigonometry ratios by songs.

All the ratios in the trigonometry

Are between 1 and 0 .

$\operatorname{Sin} 30^{\circ}=\frac{\frac{1}{2}}{\sqrt{3}}$
$\operatorname{Cos} 30^{\circ}=\frac{\sqrt{2}}{\sqrt{3}}$
$\operatorname{Tan} 30^{\circ}=\frac{\sqrt{3}}{2}$
$\operatorname{Sin} 60^{\circ}=\frac{1}{2}$
$\operatorname{Cos} 60^{\circ}=\frac{1}{\sqrt{3}}$
$\operatorname{Tan} 60^{\circ}=\frac{1}{2}$

$$
1
$$

\section{Visual style: Learning by seeing:}

When it comes to more formal math instruction, there are specific techniques that will help make it more accessible to visual learn. They prefer the study materials like charts, filmstrips, notes and flashcards, a picture is a worthy way more than a thousand words, so seeing math problems represented in 3D cartoon format is incredibly useful. Almost every child's educational software publisher has created at least one math program for children.

\section{Examples:}

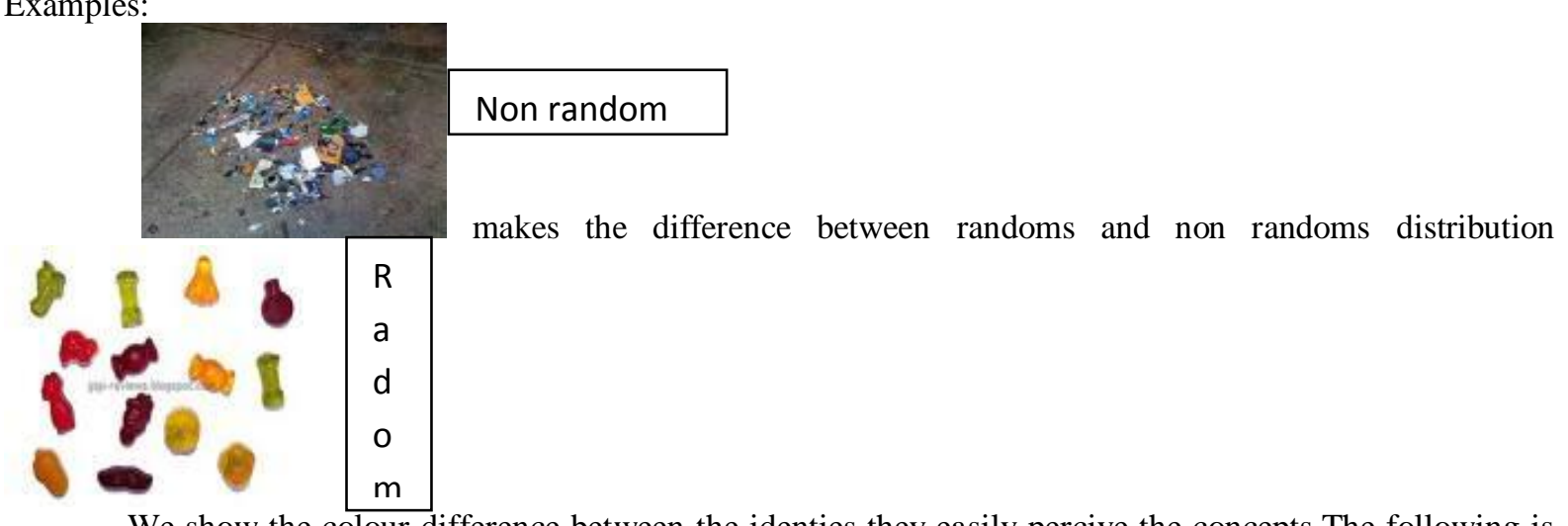

We show the colour difference between the identies they easily percive the concepts. The following is the examples for it.

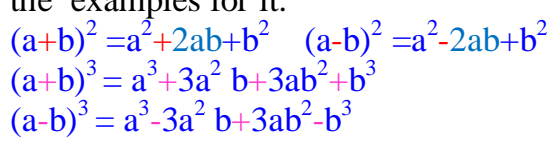

\section{IV.}

\section{Educational Implications:}

$>$ Being abstract nature of mathematics it is difficult for the students to learn mathematics. Multi sensory strategies through ICT make student's attention towards their study.

$>$ It is a more effective method which brings the concepts to the memory storage for long period of time in long term memory store and enthusiasm towards their subject.

$>$ Learning by doing is more effective methodology than any other method. Multi sensory strategies fulfill all their needs.

$>\quad$ The influences of Multi sensory strategies make the mathematical activities to be undertaken and provide powerful guide to teachers making choices about pedagogical approaches and classroom organization. 
$>$ Using Multi sensory Integration strategies can help pupils to access, select and interpret information, recognize patterns, accuracy, review and modify their work to improve the quality, communicate with others and present information, evaluate their work, improve their efficiency, be creative and take risks, gain confidence and independence

> Teacher should select or create mathematical tasks that take advantage of what Multi sensory Integration strategies can do effectively and well-graphing, producing dynamic images, computing and providing access to data.

$>$ Implications for Teachers

$>$ Students learn in different ways. Some learn best through listening, some by seeing and others by doing. Learning comes more easily to students when instruction is presented using all three stimuli. If lectures are used, for example, they need to be accompanied by visual aids that could be pictures, objects or cards with words or math problems. There should be opportunities for students to interact with the teacher or with other students by answering questions, taking notes or writing on the dry board.

\section{Conclusion:}

Compared to conventional method Multi-sensory Integration strategies make more enthusiasm among the learners. Awareness and applications of this method should be given through the proper training to the teachers. It is an effective method for teaching - learning process. Our present ABL \& ALM methods activities are highly related in Multi-sensory Integrated strategies. We should implement the multi-sensory strategies in higher education it will bring the quality enhancement in education as a whole.

\section{Reference:}

[1]. Dr.Swaruparani "Teaching of mathematics", 2007, APH publication, NewDelhi.

[2]. Mrs.C.Mattuvarkuzhali“'Teaching of mathematics, 2009, APH publication, NewDelhi.

[3]. www.learning disabilities.com

[4]. www.dylexia for teacher.com

[5]. www.housing.sc.edu 